\title{
The occurrence of spermiophagy under natural conditions in the cauda epididymidis of the Cape horseshoe bat (Rhinolophus capensis)
}

\author{
R. T. F. Bernard \\ Department of Zoology and Entomology, Rhodes University, Grahamstown 6140, South Africa
}

\begin{abstract}
Summary. In Cape horseshoe bats large numbers of spermatozoa remain in the cauda epididymidis after copulations have ceased in September. Light microscopy has shown that for 5 months after September phagocytes are present in the lumen of the cauda epididymidis and electron microscopy has shown these cells to be active spermiophages. The large numbers of spermiophages present suggests that these cells could be responsible for removal of most of the excess spermatozoa. Spermiophagy by the epididymal epithelial cells occurs rarely and is not significant in the treatment of excess spermatozoa.
\end{abstract}

\section{Introduction}

In many species of hibernating vespertilionid and rhinolophid bats the cauda epididymidis acts as a site of sperm storage (Strelkov, 1962; Racey, 1979). However, in the seasonally breeding Cape horseshoe bat (Rhinolophus capensis), large numbers of spermatozoa remain in the cauda epididymidis after copulations have ceased and a second function associated with the epididymis may then be the removal of excess spermatozoa.

The fate of excess or non-ejaculated spermatozoa in mammals has been investigated and there appear to be four possible ways in which these spermatozoa may be removed. (1) Under natural conditions luminal macrophages may remove decapitate spermatozoa from the epididymis of the bull, monkey and rabbit (Bedford, 1965; Roussel, Stallcup \& Austin, 1967). Under the abnormal conditions of vasoligation, vasectomy and azoospermia, spermiophagy by macrophages occurs in man (Phadke \& Phadke, 1961; Phadke, 1964), rhesus monkey (Alexander, 1972; Bedford, 1976), mouse (Neaves, 1975) and hamster (Bedford, 1976). (2) It has been reported that spermatozoa undergo dissolution or degradation in the lumen of the epididymis of the guinea-pig (Simeone \& Young, 1931), rabbit (Orgebin-Crist, 1969), rat (Cooper \& Hamilton, 1977), hamster (Flickinger, Howards \& English, 1978), rock hyrax (Millar, 1972) and European mole (Suzuki \& Racey, 1976). The fate of the products of sperm dissolution is not known. (3) The ability of the epididymal epithelium to absorb colloidal material and vital dyes by micropinocytosis has been widely reported (Shaver, 1954; Burgos, 1964; Nicander, 1965) but only in very few cases has it been shown that these cells are capable of absorbing portions of spermatozoa (rabbit : Nicander, 1965; Glover, 1969; rat: Flickinger, 1972; mouse: Neaves, 1975). (4) In several species it has been shown that spermatozoa may be voided by spontaneous ejaculation, in seminal discharges or in the urine and in such species these may be the most important means of removing excess spermatozoa (Orbach, 1961 ; Martan \& Risley, 1963; Lino, Braden \& Turnbull, 1967; Martan, 1969).

For two species of microchiropteran bat (Myotis lucifugus and $M$. velifer) it has been suggested that, in the absence of macrophages and occurrence of only limited sperm dissolution, the excess 
spermatozoa in the cauda epididymidis are probably voided during urination (Krutzsch, Crichton \& Nagle, 1982). Males of the genus Rhinolophus from subtropical and temperate zone latitudes store spermatozoa in the cauda epididymidis during winter hibernation (Gustafson, 1979), and in the Cape horseshoe bat ( $R$. capensis) large numbers of spermatozoa remain in the cauda epididymidis after the spring copulations. The aim of this study was to investigate the fate of these non-ejaculated spermatozoa.

\section{Materials and Methods}

Specimens of the Cape horseshoe bat (Rhinolophus capensis) were collected every month from Table Farm ( $\left.33^{\circ} 17^{\prime} \mathrm{S}, 26^{\circ} 25^{\prime} \mathrm{E}\right)$ in the Cape Province of South Africa, brought back to the laboratory and killed by asphyxiation with $\mathrm{CO}_{2}$.

Light microscopy. Epididymides were removed from the specimens, fixed in Bouin's fluid for about 2 weeks and thereafter stored in $70 \%$ alcohol. Tissues were embedded in Paraplast, sectioned at $5 \mu \mathrm{m}$ and stained with Ehrlich's haematoxylin and eosin.

Electron microscopy. Pieces of cauda epididymidis $\left(4 \mathrm{~mm}^{3}\right)$ were fixed in cold $\left(4^{\circ} \mathrm{C}\right) 5 \%$ glutaraldehyde in $0.1 \mathrm{M}$-phosphate buffer ( $\mathrm{pH} \mathrm{7.3)}$ for 3 days. After primary fixation the tissues were washed in $0.1 \mathrm{M}$-phosphate buffer, secondarily fixed in $1 \%$ osmium tetroxide for $90-100 \mathrm{~min}$ and washed again. After rapid dehydration through an alcohol sequence the tissues were embedded in Taab 812. Thick sections were cut with a glass knife on an LKB UM III ultramicrotome, stained with toluidine blue and examined with a light microscope. Ultrathin sections were cut with a glass knife, picked up on copper grids, stained with aqueous uranyl acetate (Watson, 1958) and lead citrate (Reynolds, 1963) and examined under a Jeol JEM-100 II transmission electron microscope.

The density of macrophages per unit area in the lumen of the cauda epididymidis was calculated from light microscope sections. The numbers of macrophages in 20 transverse sections through the lumen of the epididymis of each specimen were counted and the area of the lumen was calculated from the radius. With thickness of the sections known $(5 \mu \mathrm{m})$ the number of macrophages per unit volume was calculated.

\section{Results}

Ín Cape horseshoe bats spermatogenesis occurred in summer (September to April) and spermatozoa were first released to the epididymides in April. Between May and August these animals hibernated and during this period spermatozoa were stored in the cauda epididymidis (Pl. 1, Fig. 1). Although copulation, which was asynchronous within the population, occurred in August

\section{PLATE 1}

Fig. 1. Section through the cauda epididymidis of a Cape horseshoe bat showing the typical appearance of this structure during the period of sperm storage before fertilization. $\times 106$.

Fig. 2. Section through the cauda epididymidis in December, showing the numerous phagocytes (arrows) amongst the stored spermatozoa. $\times 394$.

Fig. 3. Section through the cauda epididymidis in March, showing the reduced numbers of phagocytes (arrows) and spermatozoa. $\times 450$.

Fig. 4. Light micrograph of a section through the cauda epididymidis, showing the typical appearance of the phagocytes (arrows). $\times 680$. 
PLATE 1
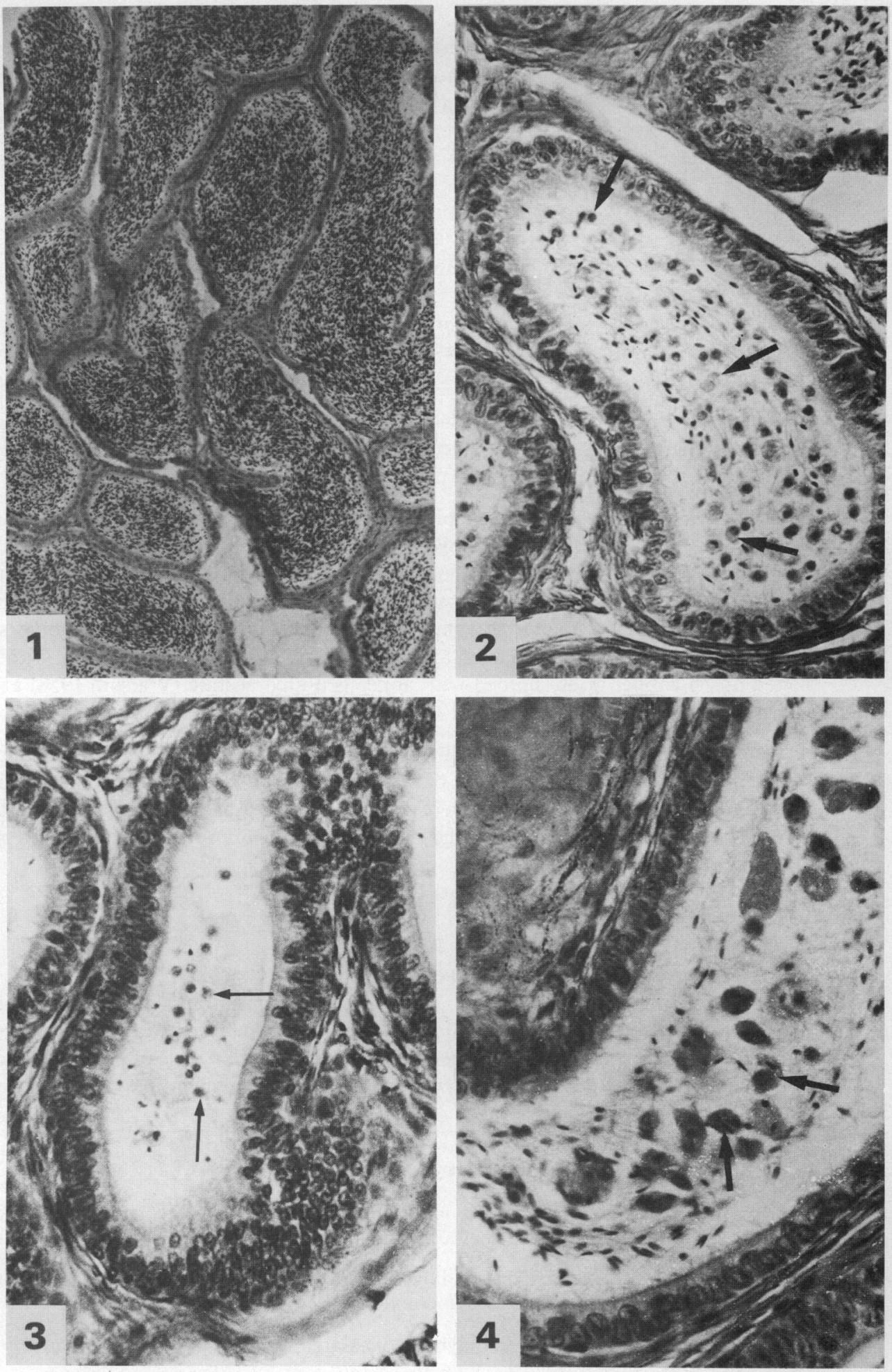

(Facing p. 540) 
PLATE 2
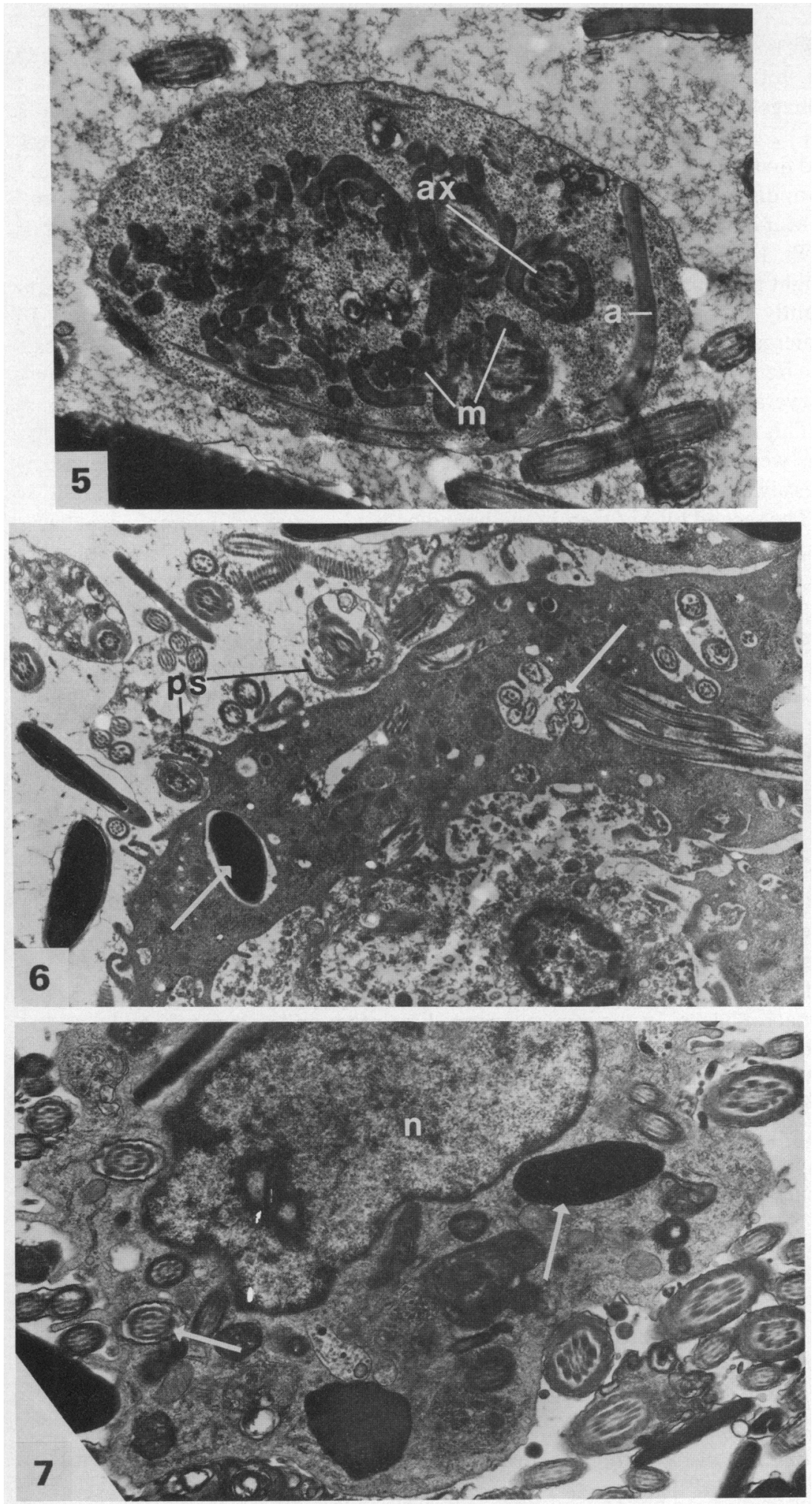
and September, large numbers of spermatozoa remained in the cauda epididymidis until February so that sperm storage effectively occurred between April and February.

Luminal phagocytes were present in very small numbers $\left(1.8 \pm 1.1\right.$ macrophages per $10 \times 10^{3}$ $\mu \mathrm{m}^{3}$; mean \pm 2 s.d.) in the cauda epididymidis during the period of sperm storage before copulation and first became abundant in October. Between October and February the lumen of the cauda epididymidis contained large numbers of phagocytes $\left(25 \pm 10.5\right.$ per $\left.10 \times 10^{3} \mu \mathrm{m}^{3}\right)(\mathrm{Pl}$. 1 , Fig. 2) but by March the numbers of spermatozoa and phagocytes were reduced $(6 \cdot 6 \pm 2 \cdot 71$ per 10 $\left.\times 10^{3} \mu \mathrm{m}^{3}\right)$ (Pl. 1, Fig. 3).

With the light microscope, the phagocytes appeared as round or ovoid cells of 5-20 $\mu \mathrm{m}$ in diameter with lightly staining eosinophilic cytoplasm and a large, central nucleus (P1. 1, Fig. 4).

Electron microscopy showed that two different types of membrane-bound body appeared to be involved in the removal of excess spermatozoa. The first was uncommon and appeared more as an aggregate of several spermatozoa within a common cell membrane than a typical phagocytic cell (P1. 2, Fig. 5). This membrane-bound body was characterized by a granular cytoplasm, in which the sperm portions were lying free, and an apparent lack of nucleus and other organelles. Although these structures always contained portions of spermatozoa, they were never seen actively engulfing spermatozoa. The second type of membrane-bound body was a typical macrophage, characterized by a varied shape and numerous pseudopodial projections (Pl. 2, Figs 6 \& 7). Cellular organelles included a large nucleus of varied shape, mitochondria, primary and secondary lysosomes, various vacuoles, Golgi apparatus and some endoplasmic reticulum. These macrophages were active spermiophages, engulfing numerous spermatozoa (P1. 2. Figs $6 \&$ 7). The engulfed sperm portions always appeared in membrane-bound vacuoles within the macrophage cytoplasm.

The epithelium of the cauda epididymidis showed considerable micropinocytotic activity but there was little evidence of spermiophagy by the epithelial cells. On three occasions only, sections of sperm tail were seen in the cytoplasm of the principal epididymal cells.

\section{Discussion}

From the available literature it is apparent that the fate of excess spermatozoa may vary both from species to species and within a single species. In the seasonally breeding rock hyrax, Procavia capensis, spermatozoa that remain in the cauda epididymidis after copulations have ended are degraded (Millar, 1972), while in Cape horseshoe bats (present study) such spermatozoa are destroyed by macrophages. In the mouse, sperm dissolution and spermiophagy by macrophages occur after vasoligation (Neaves, 1975). The destruction of spermatozoa by macrophages, as described in the present study, occurs widely in mammals under unnatural conditions in which the normal expulsion of spermatozoa is prevented. However, under normal conditions macrophages rarely occur in the lumen of the epididymis (Bedford, 1965; Roussel et al., 1967; Krutzsch et al., 1982). The Cape horseshoe bat seems to be an exception to this observation with macrophages being at least partly responsible for the removal of excess spermatozoa. Phagocytes, identified from

\section{PLATE 2}

Fig. 5. A cellular aggregate, containing portions of spermatozoa within a common cell membrane. Note that the sperm portions ( $a x=$ axoneme complex; $m=$ mitochondria; $a=$ acrosome) are free in the cytoplasm of the aggregate. $\times 15225$.

Fig. 6. Part of a typical macrophage from the cauda epididymidis, showing the pseudopodial processes (ps) and disruption of ingested portions of spermatozoa (arrows). $\times 9310$.

Fig. 7. Electron micrograph of a typical macrophage, showing the large central nucleus (n) and ingested portions of spermatozoa (arrows). $\times 9750$. 
light microscope sections, are believed to serve a similar function in Geoffroy's horseshoe bat (Rhinolophus clivosus) (Bernard, 1984) and spermiophagy by macrophages may be a characteristic of this genus.

The first type of membrane-bound body described in the present study is similar in appearance to a membrane-bound structure that occurs in the epididymis of the bats Myotis lucifugus and $M$. velifer and which was seen to contain various sperm parts (Krutzsch et al., 1982). These membranelimited bodies appear to be associated with treatment of excess spermatozoa although their mode of function and origin are unknown.

The origin of the luminal macrophages in Cape horseshoe bats is unknown. Reid \& Cleland (1957) first described the halo cells in the epididymal epithelium and suggested that they may be phagocytes, and ultrastructural studies have since shown the halo cells to be morphologically similar to leucocytes (Bedford, 1965; Dym \& Romrell, 1975; Hamilton, 1975). Although it is not possible to identify the halo cells as leucocytes on the basis of morphological evidence alone, it has been suggested that they may be lymphocytes moving from the blood stream through the epididymal epithelium into the lumen (Hoffer, Hamilton \& Fawcett, 1973). The halo cells of Cape horseshoe bats were similar in appearance to those illustrated by Hoffer et al. (1973) but were at no time sufficiently numerous to account for the large number of luminal macrophages.

Bedford (1976) and Temple-Smith \& Bedford (1978) have suggested that spermiophagy only occurs under the unnatural conditions of vasectomy wherein the epididymal lumen is exposed to the immune system following rupture of the epithelium. However, it is unlikely that this is the case in Cape horseshoe bats in which the luminal macrophages occur under natural conditions and histological examination has revealed no breaks in the epithelium. Spermiophagy by epididymal epithelial cells has been reported as a rare occurrence under natural conditions (Glover, 1969; Flickinger, 1972; Neaves, 1975) and is probably not significant in the removal of excess spermatozoa. In Cape horseshoe bats the epididymal epithelial cells showed active micropinocytosis and it is possible that the ingestion of sperm fragments was fortuitious.

This work was supported by a grant from Rhodes University. I thank Rob Cross and Alex Hartley for technical assistance and several collegues for commenting on this manuscript.

\section{References}

Alexander, N.J. (1972) Vasectomy: long term effects in the rhesus monkey. J. Reprod. Fert. 31, 399-406.

Bedford, J.M. (1965) Changes in the fine structure of the rabbit sperm head during passage through the epididymis. J. Anat. 99, 891-906.

Bedford, J.M. (1976) Adaptations of the male reproductive tract and the fate of spermatozoa following vasectomy in the rabbit, rhesus monkey, hamster and rat. Biol. Reprod. 14, 118-142.

Bernard, R.T.F. (1984) Reproduction of Rhinolophus clivosus (Microchiroptera) in Natal, South Africa. $Z$. Saügetierk. 48, 321-329.

Burgos, M.H. (1964) Uptake of colloidal particles by cells of the caput epididymidis. Anat. Rec. 148, 517525.

Cooper, T.G. \& Hamilton, D.W. (1977) Observations on destruction of spermatozoa in the cauda epididymidis and proximal vas deferens of non-seasonal mammals. Am. J. Anat. 149, 93-110.

Dym, M. \& Romrell, L.J. (1975) Intraepithelial lymphocytes in the male reproductive tract of rats and rhesus monkeys. J. Reprod. Fert. 42, 1-7.
Flickinger, C.J. (1972) Alterations in the fine structure of the rat epididymis after vasectomy. Anat. Rec. 173, 277-300.

Flickinger, C.J., Howards, S.S. \& English, H.F. (1978) Ultrastructural differences in efferent ducts and several regions of the epididymis of the hamster. $\mathrm{Am}$. J. Anat. 152, 557-586.

Glover, T.D. (1969) Some aspects of function in the epididymis. Int. J. Fert. 14, 216-221.

Gustafson, A.W. (1979) Male reproductive patterns in hibernating bats. J. Reprod. Fert. 56, 403-416.

Hamilton, D.W. (1975) Structure and function of the epithelium lining the ductuli efferentes, ductus epididymidis, and ductus deferens in the rat. In Handbook of Physiology, Sect. 7, Vol. V, pp. 259-301. Eds D. W. Hamilton \& R. O. Greep. American Physiological Society, Washington, D.C.

Hoffer, A.P., Hamilton, D.W. \& Fawcett, D.W. (1973) The ultrastructure of the principal cells and intraepithelial leucocytes in the initial segment of the rat epididymis. Anat. Rec. 175, 169-202. 
Krutzsch, P.H., Crichton, E.G. \& Nagle, R.B. (1982) Studies on prolonged spermatozoa survival in Chiroptera: a morphological examination of storage and clearance of intrauterine and cauda epididymal spermatozoa in the bats Myotis lucifugus and $M$. velifer. Am. J. Anat. 165, 421-434.

Lino, B.F., Braden, A.W.H. \& Tumbull, K.E. (1967) Fate of unejaculated spermatozoa. Nature, Lond. 213, 594595.

Martan, J. (1969) Epididymal histochemistry and physiology. Biol. Reprod. 1, 134-154.

Martan, J. \& Risley, P.L. (1963) The epididymis of mated and unmated rats. J. Morph. 113, 1-5.

Millar, R.P. (1972) Degradation of spermatozoa in the epididymis of a seasonally breeding mammal, the rock hyrax, Procavia capensis. J. Reprod. Fert. 30, 447-450.

Neaves, W.B. (1975) Biological aspects of vasectomy. In Handbook of Physiology, Sect. 7, Vol. V, pp. 383-404. Eds D. W. Hamilton \& R. D. Greep. American Physiological Society, Washington, D.C.

Nicander, L. (1965) An electron microscopical study of the absorbing cells in the posterior caput epididymidis of rabbits. Z. Zellforsch. mikrosk. Anat. 66, 829-847.

Orbach, J. (1961) Spontaneous ejaculation in the rat. Science, N.Y. 134, 1072-1073.

Orgebin-Crist, M.C. (1969) Studies on the function of the epididymis. Biol. Reprod. 1, 155-175.

Phadke, A.M. (1964) Fate of spermatozoa in cases of obstructive azoospermia and after ligation of vas deferens in man. J. Reprod. Fert. 7, 1-12.

Phadke, A.M. \& Phadke, G.M. (1961) Occurrence of macrophage cells in the semen and in the epididymis in cases of male infertility. J. Reprod. Fert. 2, 400409.
Racey, P.A. (1979) The prolonged storage and survival of spermatozoa in Chiroptera. J. Reprod. Fert. 56, 391402.

Reid, B.L. \& Cleland, K.W. (1957) The structure and function of the epididymis. Aust. J. Zool. 5, 223-252.

Reynolds, E.S. (1963) The use of lead citrate at high pH as an electron opaque stain in electron microscopy. $J$. Cell Biol. 17, 208-212.

Roussel, J.D., Stallcup, O.T. \& Austin, C.R. (1967) Selective phagocytosis of spermatozoa in the epididymis of bulls, rabbits and monkeys. Fert. Steril 18, 509-516.

Shaver, S.L. (1954) The role of stereocilia in removing india ink from the lumen of the rat epididymis. Anat. Rec. 119, 177-186.

Simeone, F.A. \& Young, W.C. (1931) A study of the function of the epididymis. IV. The fate of nonejaculated spermatozoa in the genital tract of the male guinea-pig. J. exp. Biol. 8, 163-175.

Strelkov, P. (1962) The peculiarities of reproduction in bats (Vespertilionidae) near the northern border of their distribution. Int. Symp. Meth. Mammal. Invest., Brno, pp. 306-311. Praha.

Suzuki, F. \& Racey, P.A. (1976) Fine structural changes in the epididymal epithelium of moles (Talpa europaea) throughout the year. J. Reprod. Fert. 47, 47-54.

Temple-Smith, P.D. \& Bedford, J.M. (1978) Fate of spermatozoa in the male. II. Absence of a specific sperm disposal mechanism in the androgen deficient hamster and rabbit. Biol. Reprod. 17, 791-798.

Watson, M.L. (1958) Staining of tissue sections for electron microscopy with heavy metals. J. Biophys. Biochem. Cytol. 4, 475-478.

Received 8 November 1983 